\title{
In-Depth Investigation of Statistical and Physicochemical Properties on the Field Study of the Intermittent Filling of Large Water Tanks
}

\author{
Do-Hwan Kim, ${ }^{1}$ Doo Yong Choi, ${ }^{2}$ Taeho Choi, ${ }^{2}$ and Zong Woo Geem ${ }^{3}$ \\ ${ }^{1}$ Water Quality Institute, Busan Water Authority, Busan, Republic of Korea \\ ${ }^{2} \mathrm{~K}$-water Institute, Korea Water Resources Corporation (K-water), Daejeon, Republic of Korea \\ ${ }^{3}$ Department of Energy IT, Gachon University, Seongnam, Republic of Korea \\ Correspondence should be addressed to Zong Woo Geem; zwgeem@gmail.com
}

Received 14 October 2016; Accepted 27 December 2016; Published 17 January 2017

Academic Editor: David Ayala-Cabrera

Copyright ( 2017 Do-Hwan Kim et al. This is an open access article distributed under the Creative Commons Attribution License, which permits unrestricted use, distribution, and reproduction in any medium, provided the original work is properly cited.

\begin{abstract}
Large-demand customers, generally high-density dwellings and buildings, have dedicated ground or elevated water tanks to consistently supply drinking water to residents. Online field measurement for Nonsan-2 district meter area demonstrated that intermittent replenishment from large-demand customers could disrupt the normal operation of a water distribution system by taking large quantities of water in short times when filling the tanks from distribution mains. Based on the previous results of field measurement for hydraulic and water quality parameters, statistical analysis is performed for measured data in terms of autocorrelation, power spectral density, and cross-correlation. The statistical results show that the intermittent filling interval of $6.7 \mathrm{~h}$ and diurnal demand pattern of $23.3 \mathrm{~h}$ are detected through autocorrelation analyses, the similarities of the flow-pressure and the turbidity-particle count data are confirmed as a function of frequency through power spectral density analyses, and a strong cross-correlation is observed in the flow-pressure and turbidity-particle count analyses. In addition, physicochemical results show that the intermittent refill of storage tank from large-demand customers induces abnormal flow and pressure fluctuations and results in transient-induced turbid flow mainly composed of fine particles ranging within $2-4 \mu \mathrm{m}$ and constituting $\mathrm{Fe}, \mathrm{Si}$, and $\mathrm{Al}$.
\end{abstract}

\section{Introduction}

Water utilities intend to provide safe and reliable supplies of drinking water at reasonable service levels. A reasonable service level can be defined in many ways, generally including provisions for adequate pressure, safe water quality, and reliable supply $[1,2]$. A consistent daily demand pattern may be a significant component in effectively operating a drinking-water distribution system $[3,4]$. Typically, water usage is relatively low at night when most people sleep, increases in the early morning hours as people prepare for the day, decreases in the middle of the day, and finally increases again in the early evening as people return home [2-4]. However, the typical demand pattern and operational rule can be impaired by intermittent water consumption of largedemand customers. This is because large-demand customers, frequently high-density dwellings (e.g., apartments and large condominiums) and buildings (e.g., office complexes and shopping malls), have dedicated ground or elevated tanks to consistently supply water to residents; filling these tanks from distribution mains uses large quantities of water in short periods. In the Republic of Korea, rapid urbanization has promoted the construction of many high-density dwellings and buildings. The installation of storage tanks is regulated to stabilize demand fluctuations and to store water for emergency use. The previous research of Choi et al. [5] addressed the drawbacks of intermittent filling of storage tanks through field measurements in Nonsan- (NS-) 2 district meter area (DMA) and showed unwanted pressure drops and turbidity peaks induced by localized high demand. However, further investigation of operational vulnerability should be analysed in terms of statistical, physical, and chemical analyses.

First, in hydraulic measures, localized high demand has been reported to induce low pressures and sometimes 
service interruptions in adjacent areas. This results from the friction head-loss equation in the hydraulic modelling of a water distribution system $[1,2]$. However, the effect of localized high demand on pressure fluctuations has not been quantitatively investigated. In water quality measures, various types of deposits have been reported in distribution mains; these include sediments on pipes, slimes on pipe surfaces, and adhesive corrosion products [6-10]. Under normal operating conditions, these deposits are attached to parts of the distribution system where the hydraulic conditions are favorable. Under high-flow conditions, however, the resulting high velocity can disturb the deposited materials, inducing aesthetic and/or microbial problems by the suspension of particles of the deposits in drinking water [9-12]. The effects of localized high demand on turbidity and particle counts can be significant for the intermittent water replenishment of large-demand customers.

The aim of this study is to provide an in-depth insight on hydraulic and water quality vulnerability using statistical and physicochemical parameters when large-demand customers fill their storage tanks in short timespans. To investigate the impact of intermittent refill of drinking water, time series data of Choi et al. [5] are used, measured at sampling intervals of 1 min over a 48-hour period in the NS-2 DMA in NS City in the Republic of Korea. The measured data were analysed through statistical approaches to find similarities and correlations with flow rate for pressure, turbidity, and particle counts. Three types of statistical analyses are implemented: autocorrelation to detect time intervals of the intermittent filling and diurnal demand, power spectral density to closely observe the similarities of the measured data as a function of frequency, and cross-correlation to measure the correlation of time series data as a function of the displacement one relative to the other. The effect of suspended particle load on turbidity was further investigated by collecting particulate materials and grouping them into different sizes. The concluding remarks include technical suggestions to mitigate the impact of pressure and turbidity fluctuations induced by intermittent water demand.

\section{Measurements and Methods}

2.1. Online Data Monitoring. The NS-2 DMA is part of the NS water supply zone with two large-demand customers and 966 small service connections, supplied from the Seokseong water treatment plant through the NS reservoir (see Figure 1(a)). The two large-demand customers of the Humansia and Choheung apartment blocks account for 39\% of the total recorded water consumption of $35,800 \mathrm{~m}^{3} / \mathrm{month}$. In order to effectively manage the hydraulic condition of the DMA, a flow meter and a pressure gauge have been installed with the supervisory control and data acquisition (SCADA) system. Additional real-time monitoring system was installed to measure pressure, turbidity, and particle count at the fire hydrant beside the Humansia apartment block, one of the large-demand customers in the NS-2 DMA (see Figures 1(b) and $1(\mathrm{c}))$.
A portable pressure logger (LoLogLL/Vista Data Logger, Radcom Technologies) was connected to one of the outlet nozzles of the hydrant, and the electronic signal transmitted by the pressure transducer was converted into a pressure reading. On the other side of the outlet nozzles, an online turbidimeter (1720E Turbidimeter, HACH) and particle counter (PC 2400 PS, CHEMTRAC) were installed to obtain time series data. The turbidimeter measured the turbidity of continuously flowing sample flows through a bubble removal system, which vented entrained air from the sample stream. The particle counter measured the quantity and size of particles electronically through a light beam produced by an infrared laser. A plastic chamber was used to stabilize the flow rate into the installed monitoring equipment. The measured turbidity and particle counts were stored on a laptop computer. Measurements were performed for $48 \mathrm{~h}$ beginning at 16:30 on September 3, 2013, at intervals of 1 minute.

2.2. Particle Collection and Analysis. In addition to the online monitoring system, a particulate-collecting device was installed to preconcentrate the fine particles by filtering the water through glass-fibre filters (GF/C) with pore sizes of $1.2 \mu \mathrm{m}$. The filters were prepared by rinsing in deionized water and drying in a $105^{\circ} \mathrm{C}$ oven. The collecting device was specifically manufactured to follow the concept of the multiple-particulate filtration system (MuPFiS), as shown in Figure 2(a) $[13,14]$. Fine particles are collected on the GF/C that flow through the four parallel piping lines monitored by the pressure meter. Five sets of samples at each piping line are collected as transient events occurred for 48 hours. Each set of collected samples from the four parallel piping systems weighed more than $2.5 \mathrm{mg}$ to satisfy the minimum mass detection limits. For the detection of the elemental components in the particles, the collected particulates were sent to the Centre for Research Facilities (CRF) of the Chungnam National University, an authorized analysis institution, for performing analytical procedures. The samples were analysed with the OPTIMA 4300 DV inductively coupled plasma atomic emission spectroscope (ICP-AES) with a resolution of $0.006 \mathrm{~nm}$ at $200 \mathrm{~nm}$.

2.3. Statistical Analysis for Time Series Data. To analyse the similarity between the online monitored parameters, statistical analysis was performed on the time series data. Statistical analysis has been widely applied in hydrologic and environmental engineering $[15,16]$. More specifically, in the field of water supply systems, time series modelling has been implemented in analysing demand patterns and leak detection $[17,18]$. The time series modelling employed in this study is correlation and power spectral density.

Correlation relates to the interdependency of two variables (e.g., $x$ and $y$ ) as a function of the lag of one relative to the other, defined as follows:

$$
r_{x y}=\frac{\sum(x-\bar{x})(y-\bar{y}) / n}{\sigma_{x} \sigma_{y}},
$$




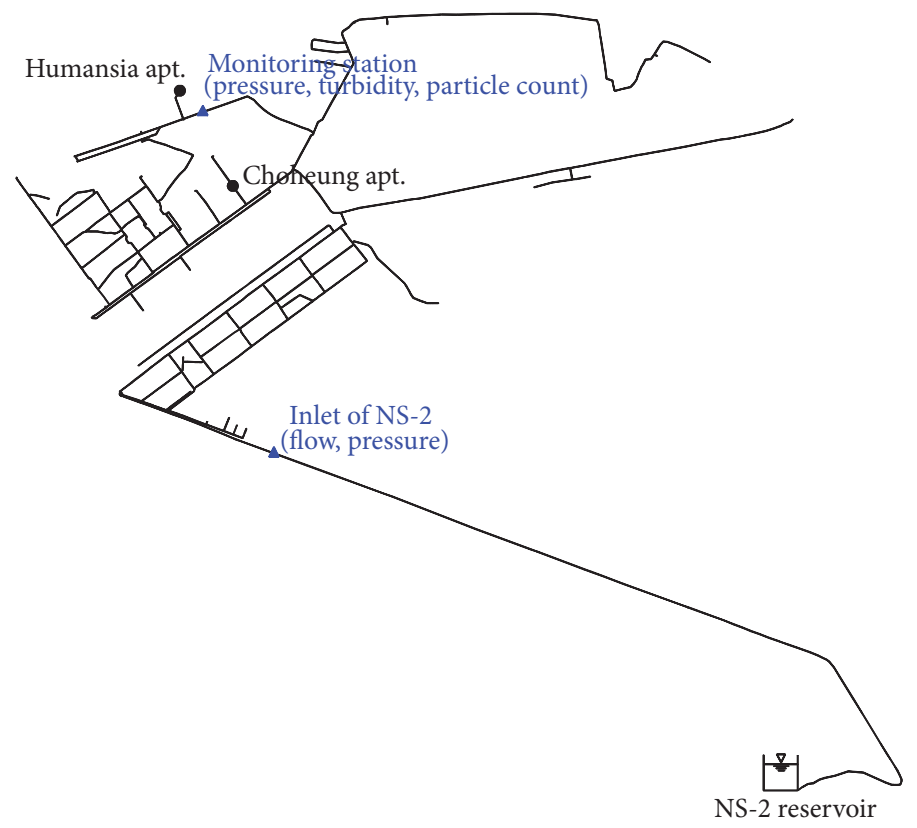

(a) Layout of field study area

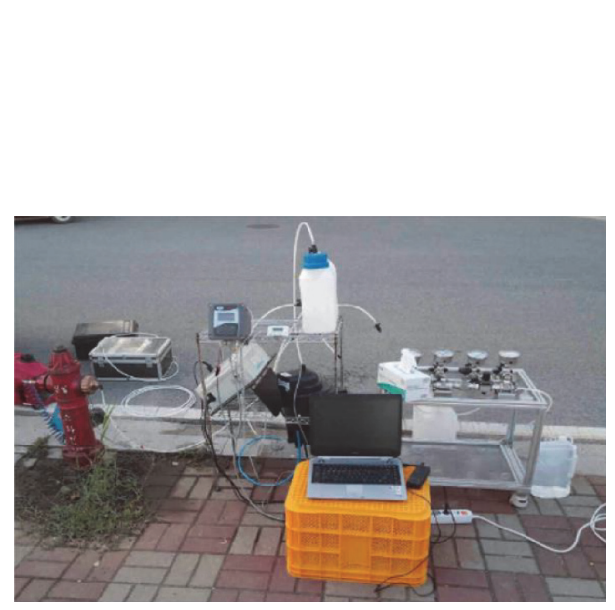

(b) Experimental setup

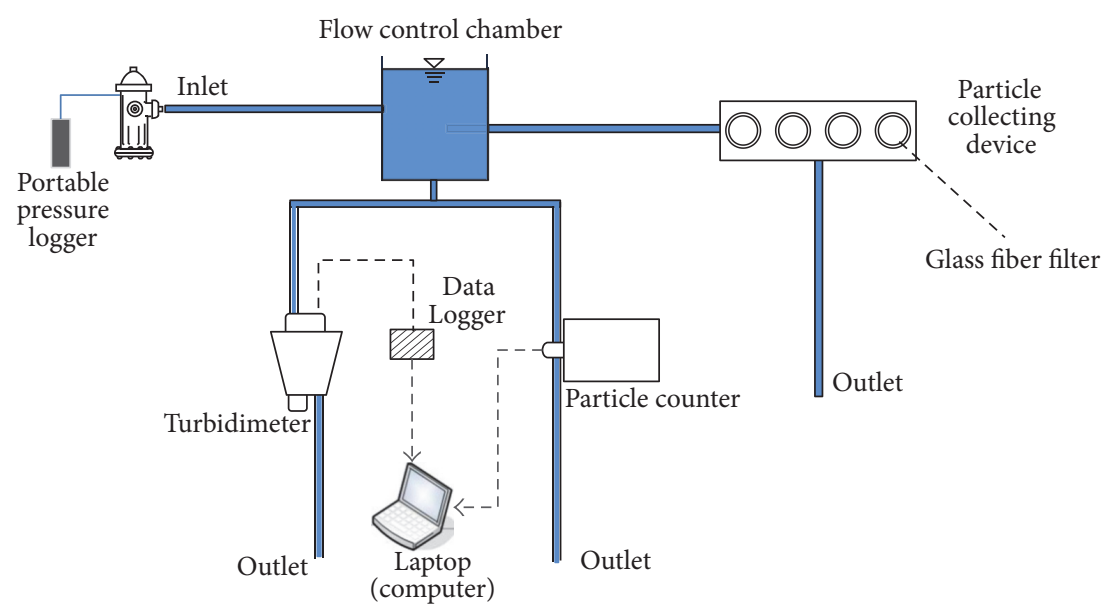

(c) Measuring system

FIGURE 1: Monitoring system installed at the monitoring station of NS-2 DMA.

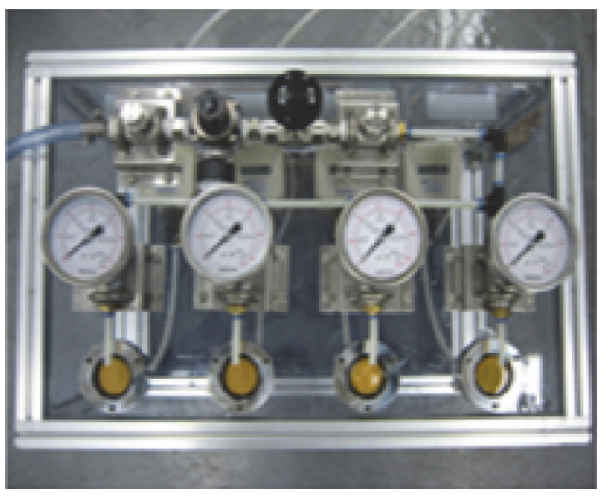

(a) Particle collector

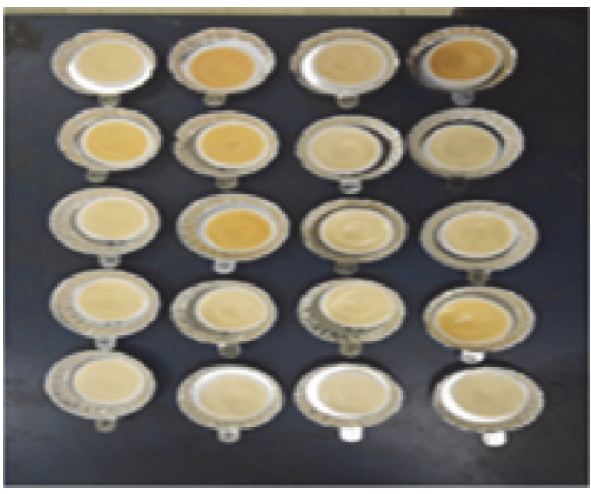

(b) Filtered sample with GF/C

FIGURE 2: Particulate sampling device and glass-fibre filter. 
TABLE 1: Basic statistics of hydraulic and water quality data in NS-2 DMA.

\begin{tabular}{|c|c|c|c|c|}
\hline \multirow{2}{*}{ Variable } & \multicolumn{4}{|c|}{ Basic statistics } \\
\hline & Minimum & Maximum & Mean & Std. deviation \\
\hline$Q_{\text {in }}\left(\mathrm{m}^{3} / \mathrm{h}\right)$ & 13.92 & 178.04 & 55.84 & 38.95 \\
\hline$P_{\text {in }}\left(\mathrm{kgf} / \mathrm{cm}^{2}\right)$ & 2.14 & 3.86 & 3.18 & 0.35 \\
\hline$P_{\mathrm{ms}}\left(\mathrm{kgf} / \mathrm{cm}^{2}\right)$ & 2.39 & 3.74 & 3.34 & 0.31 \\
\hline $\mathrm{TB}_{\mathrm{ms}}(\mathrm{NTU})$ & 0.04 & 2.27 & 0.13 & 0.16 \\
\hline \multicolumn{5}{|l|}{$\mathrm{PC}_{\mathrm{ms}}(\# / \mathrm{mL})$} \\
\hline $1-2 \mu \mathrm{m}$ & 0.00 & 616.28 & 22.37 & 47.01 \\
\hline $2-4 \mu \mathrm{m}$ & 0.00 & $3,032.40$ & 94.45 & 235.43 \\
\hline $4-6 \mu \mathrm{m}$ & 0.00 & $1,434.50$ & 36.46 & 85.11 \\
\hline $6-10 \mu \mathrm{m}$ & 0.00 & 370.00 & 15.50 & 21.78 \\
\hline $10-15 \mu \mathrm{m}$ & 0.00 & 54.80 & 8.97 & 5.88 \\
\hline $15-20 \mu \mathrm{m}$ & 0.00 & 20.16 & 5.78 & 3.29 \\
\hline $20-30 \mu \mathrm{m}$ & 0.00 & 16.83 & 4.24 & 2.60 \\
\hline $30-32 \mu \mathrm{m}$ & 0.00 & 4.66 & 0.74 & 0.53 \\
\hline
\end{tabular}

where $\bar{x}, \bar{y}, \sigma_{x}$, and $\sigma_{y}$ are the means and standard deviations for $x$ and $y$ and $n$ is the sample size. The correlation (or cross-correlation) coefficient $r_{x y}$ is a dimensionless number between -1 and +1 . Autocorrelation is the correlation of one variable (e.g., $x$ ) with itself at different points in time. The autocorrelation coefficient with a lag time $k$ is calculated as

$$
r_{k}=\frac{\sum\left(x_{t}-\bar{x}\right)\left(x_{t-k}-\bar{x}\right) / n}{\sigma_{x} \sigma_{x}} .
$$

Again, $r_{k}$ ranges from -1 to +1 . From the correlation of $x_{t}$ and $x_{t}, r_{0}=1$.

The power spectral density in the frequency domain represents the periodicity of the time series variable by converting the data to the frequency domain. For a discretely sampled time series $x_{n}$, the discrete Fourier coefficients are given by

$$
X(k)=\sum_{n=0}^{N-1} x_{n} e^{-i(2 \pi / N) n k} \quad k=0,1,2,3, \ldots, N-1,
$$

where $x_{k}$ is the Fourier coefficient at $2 \pi k / N$ and $N$ is the record length. The power of the $k$ th frequency is $|X(k)|^{2}$ and the power spectral density at frequency $k$ is $|X(k)|^{2} / N$.

\section{Results and Discussion}

The time series pressure, turbidity, and particle count data are first analysed in terms of the variation of flow rate induced by the intermittent replenishment of large-demand apartments. Then, the statistical results of autocorrelation, spectral density, and cross-correlation are presented with explanations of each parameter. Lastly, the ICP-AES results are presented to characterize the major elements of the collected particulates.

3.1. Time Series Data of Hydraulic and Water Quality Parameters. The intermittent refill of water causes unique hydraulic patterns of flow and pressure and water quality patterns of turbidity and particle count as shown in Figure 3. The basic statistics of the time series data of Figure 3 are summarized in Table 1.

For the flow data in Figure 3(a), the peak flows reach 100 to $250 \%$ of the mean flow rate of $55.89 \mathrm{~m}^{3} / \mathrm{h}$ because of the intermittent replenishment of the two large-demand customers. For pressure (Figures 3(b) and 3(c)), no distinct difference is found between the data measured at the inlet of NS-2 DMA and the monitoring station, which is due to the unnoticeable variation in elevation and short distance between the two stations. Regardless of the insignificant pressure variation, it should be noted that pressure drops of 0.5 to $1.0 \mathrm{kgf} / \mathrm{cm}^{2}$ can result from intermittent water use. This may eventually induce service interruptions by reducing the operation pressure at low-pressure DMAs. From the real-time turbidity results as shown in Figure 3(d), turbidity fluctuations do not coincide exactly with flow variations, and turbidity shows a steady concentration even when the flow rate changes drastically in the period from September 3 16:30 to September 516:30. Qualitatively, however, the sudden increase of turbidity can be speculated to be caused by intermittent flow variation. The turbidity has a low value during periods of stable flow and pressure. The peaks in turbidity do not closely match the times at which hydraulic transient events occur, but individual particles of the total suspended or dissolved solids require a delay time to travel the length of the pipe at the average velocity of the carrier water. The most important issue is that the turbidity can momentarily exceed the maximum contaminant level (MCL, usually 0.5 to 1.0 NTU) when hydraulic transient events occur by intermittent water refill. A peak turbidity of $2.27 \mathrm{NTU}$, which is 17 times the average turbidity ( 0.13 NTU), was recorded in this measurement. Although the particles inducing high turbidity may settle in the grounded or elevated tanks of large-demand customers, these settled particles may still potentially be discharged from customer taps. More significant hazards may occur in neighboring individual households directly connected to the distribution mains. Along with turbidity, the particle counts are continuously measured to analyse 


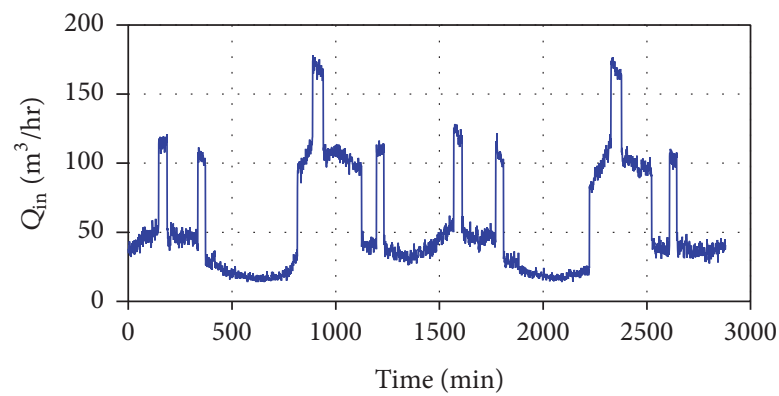

(a)

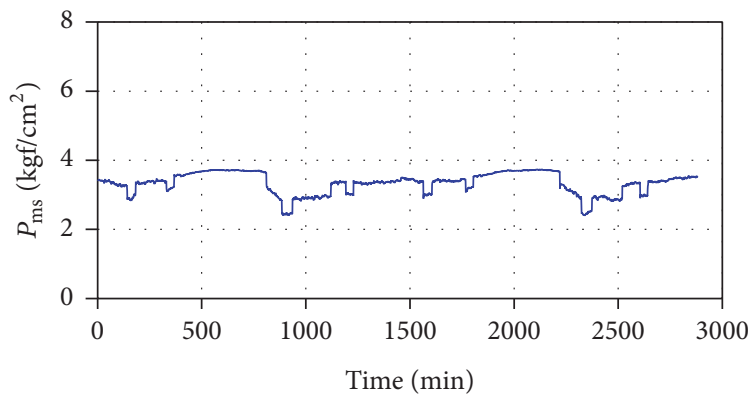

(c)

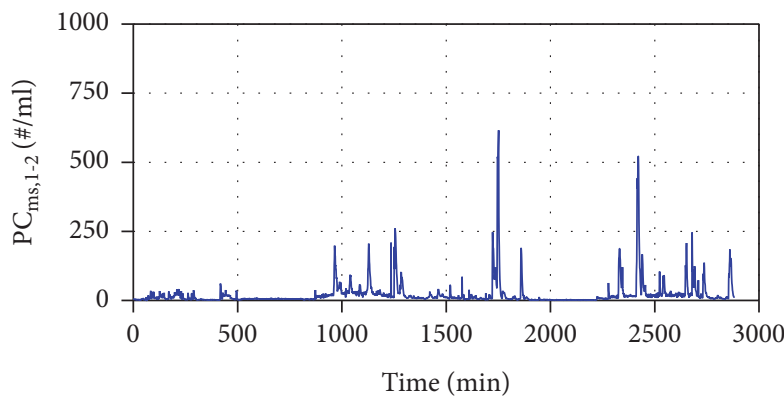

(e)

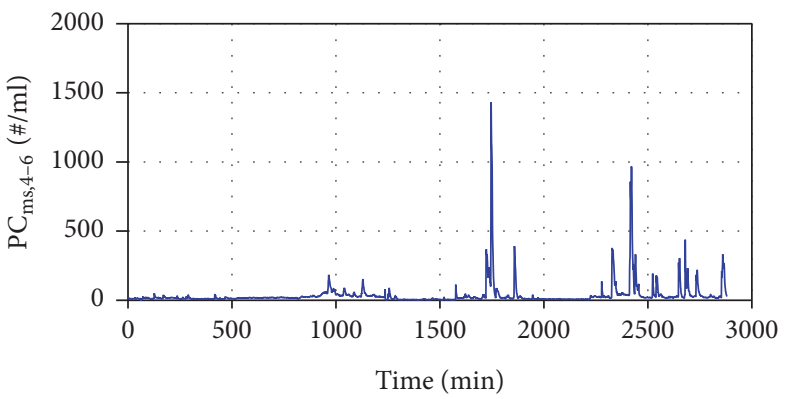

(g)

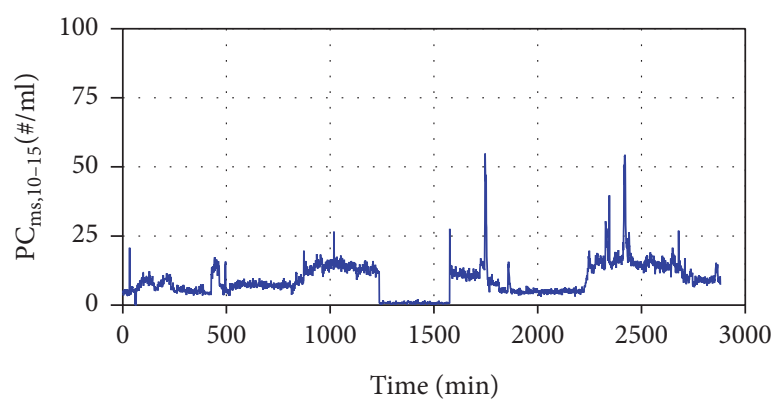

(i)

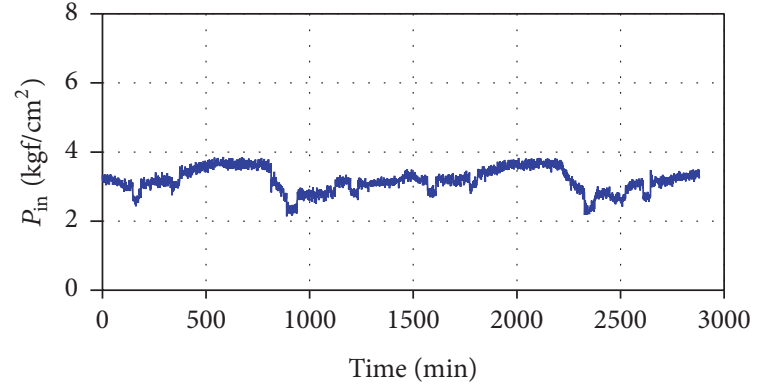

(b)

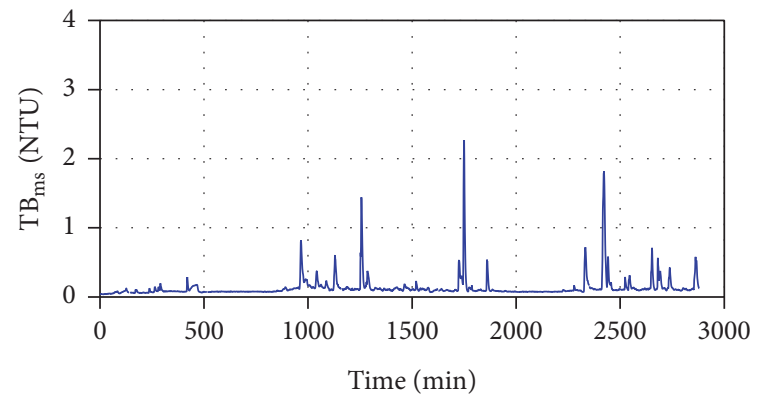

(d)

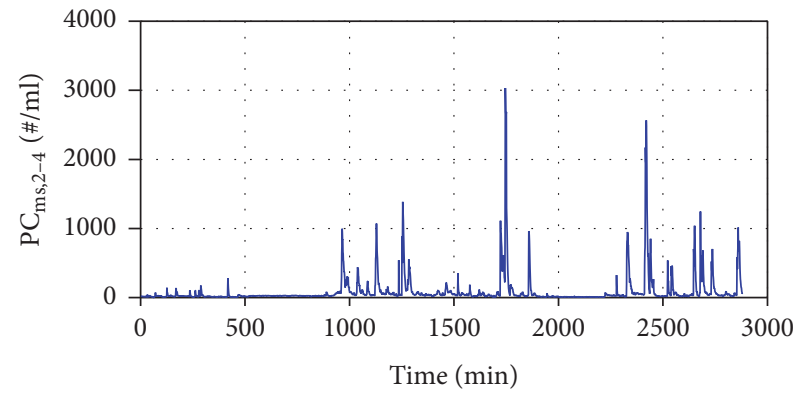

(f)

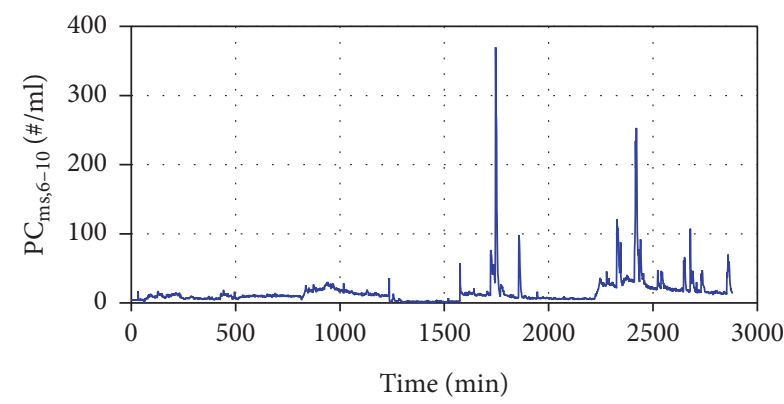

(h)

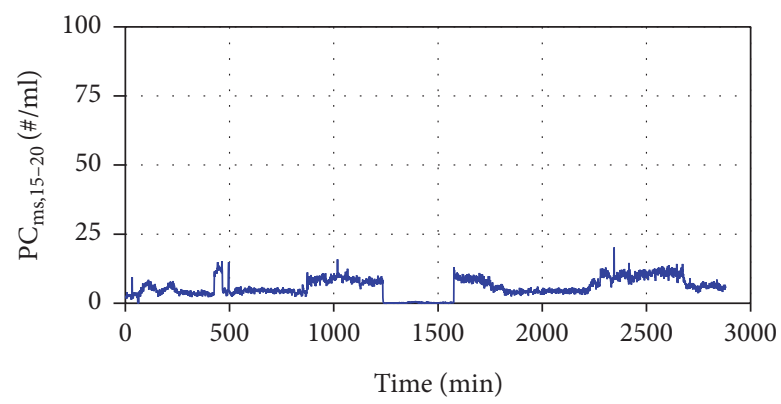

(j)

FIGURE 3: Continued. 


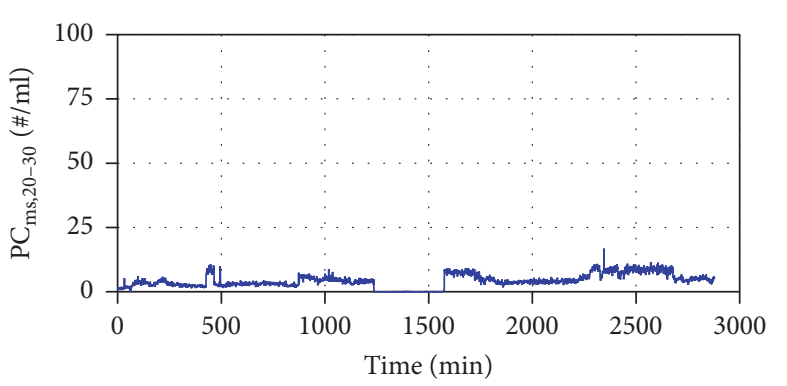

$(\mathrm{k})$

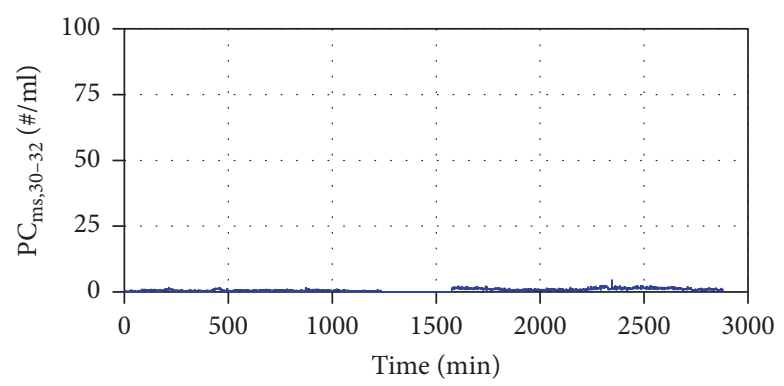

(l)

Figure 3: Time series data measured for (a) flow at the inlet $\left(Q_{\text {in }}\right),(b)$ pressure at the inlet $\left(P_{\text {in }}\right),(\mathrm{c})$ pressure at monitoring station $\left(P_{\mathrm{ms}}\right),(\mathrm{d})$ turbidity at monitoring station $\left(\mathrm{TB}_{\mathrm{ms}}\right)$ measured in nephelometric turbidity units (NTU), and $(\mathrm{e})-(\mathrm{j})$ particle count at monitoring station $\left(\mathrm{PC}_{\mathrm{ms}}\right)$.

the number of particles and the size distribution thereof, as shown in Figures 3(e)-3(j). Eight size regimes are specified from $1 \mu \mathrm{m}$ to $32 \mu \mathrm{m}$ in diameter. In the figure, the particle counts have a time series pattern similar to that of turbidity. Particles of $2-4 \mu \mathrm{m}$ are particularly prevalent, and $4-6$ and 6-10 $\mu \mathrm{m}$ particles are ranked the second- and third-most prevalent. This can be interpreted as a demonstration of the vulnerability of fine particles to the disturbance of hydraulic transient events.

3.2. Statistical Analysis and Discussion. The autocorrelations and power spectral densities of the measured data are plotted in Figure 4, excepting the pressure measured at the inlet of NS-2 DMA, because the results are expected to have similar patterns of pressure at the monitoring station, as shown in Figures 3(b) and 3(c). Regarding particle counts, the most prevalent size regime of $2-4 \mu \mathrm{m}$ is chosen for statistical analysis. As expected, the autocorrelation of flow$\left(\mathrm{Q}_{\mathrm{in}}{ }^{-}\right)$pressure $\left(P_{\mathrm{ms}}\right)$ and turbidity- $\left(\mathrm{TB}_{\mathrm{ms}}{ }^{-}\right)$particle count $\left(\mathrm{PC}_{\mathrm{ms}}\right)$ show similarity in both pattern and magnitude. In particular, the flow and pressure have the lowest negative autocorrelation of -0.45 at $400 \mathrm{~min}(6.7 \mathrm{~h})$ of lag time, indicating the time interval of intermittent replenishment from large-demand customers, and the highest positive correlation of 0.45 at $1,400 \mathrm{~min}(23.3 \mathrm{~h})$ of lag time, indicating the time interval from the diurnal demand pattern. In the plots of power spectral density, the flow- $\left(Q_{\mathrm{in}^{-}}\right)$pressure $\left(P_{\mathrm{ms}}\right)$ and the turbidity- $\left(\mathrm{TB}_{\mathrm{ms}}{ }^{-}\right)$particle count $\left(\mathrm{PC}_{\mathrm{ms}}\right)$ have similar patterns, respectively, with the highest densities in the range of $1.0-5.0 \times 10^{-5} \mathrm{~Hz}$ (equivalent to $5.6-27.8 \mathrm{~h}$ ). In particular, the similarity between turbidity and particle count can be confirmed through a closer observation for the strength of frequency. However, this result is insufficient to explain the periodic similarities in the measured data; it may be understood that the online time series data are too small to permit comparisons of periodicity in the frequency domain.

The interdependencies between pairs of measured parameters, which are flow- $\left(Q_{\text {in }^{-}}\right)$pressure $\left(P_{\mathrm{ms}}\right)$, flow$\left(\mathrm{Q}_{\mathrm{in}}{ }^{-}\right)$turbidity $\left(\mathrm{TB}_{\mathrm{ms}}\right)$, flow- $\left(\mathrm{Q}_{\mathrm{in}}{ }^{-}\right)$particle count $\left(\mathrm{PC}_{\mathrm{ms}}\right)$, and turbidity- $\left(\mathrm{TB}_{\mathrm{ms}}{ }^{-}\right)$particle count $\left(\mathrm{PC}_{\mathrm{ms}}\right)$, are shown in terms of cross-correlation functions with respect to lag times in Figure 5. As shown in Figure 5(a), the flow and pressure have a strong inverse relation at a lag time of $0 \mathrm{~min}$, and a direct proportionality is established at the lag time of $\pm 400 \mathrm{~min}$. The strong cross-correlation can also be found in the turbidity-particle count at the lag time of 0 , but no correlation occurs at other lag times (see Figure 5(d)). Crosscorrelations of flow-turbidity and flow-particle count occur periodically with small magnitudes, and it is noteworthy that the nine extreme values of the cross-correlations are the same number of extreme values of flow-pressure crosscorrelation (see Figures 5(b) and 5(c)). From the statistical analyses of autocorrelation, power spectral density, and cross-correlation, it can be concluded that the hydraulic and water quality parameters are somewhat correlated in spite of sedimentation time delay. Further statistical analysis (e.g., dynamic time warping) is necessary to measure the similarity among these time series parameters.

3.3. Chemical Element Analysis for Particles Collected. The particles collected through the particle sampling device are analysed using ICP-AES, as shown in Table 2, to investigate the chemical elements of the particles; the particle composition offers much information on the nature of the particles and the processes involved in the change of water quality in the water distribution system. From the ICP-AES results for the five sets of samples, $\mathrm{Fe}$ is the chief constituent of the particulates, attributed to the formation of a metallic oxide induced by the internal corrosion of pipelines in this study area. The other major components of the particles are Si that may result from the soil composition and $\mathrm{Al}$ that may result from the overuse of Al-containing coagulants. Similar results were found in Verberk et al. [19] and Gerke et al. [20].

\section{Conclusions}

This study addressed the problems in hydraulics and water quality induced by the intermittent replenishment of largedemand customers under the practical operation conditions of water utilities. To demonstrate the effects of intermittent refill, a real-time field experiment was performed at the NS2 DMA of NS City in Korea. The measured time series data of flow, pressure, turbidity, and particle count were analysed with statistical methods including autocorrelation, spectral 


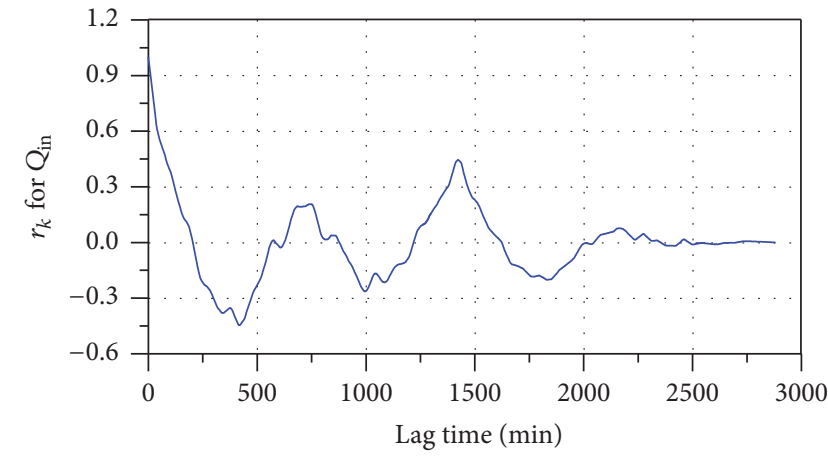

(a)

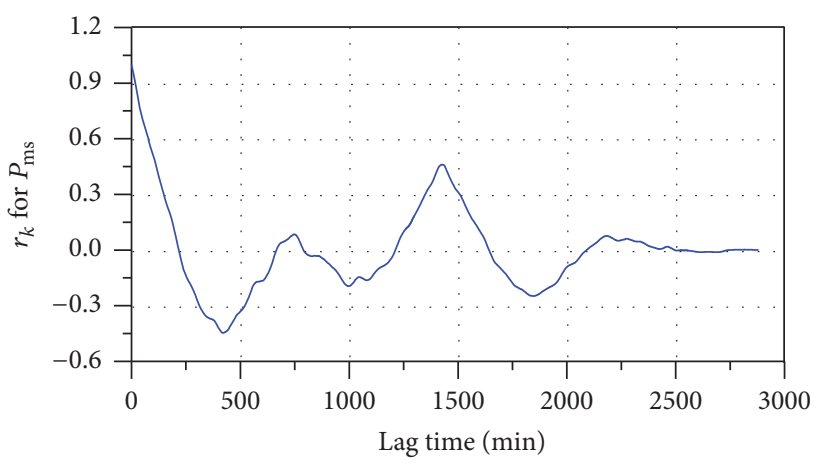

(c)

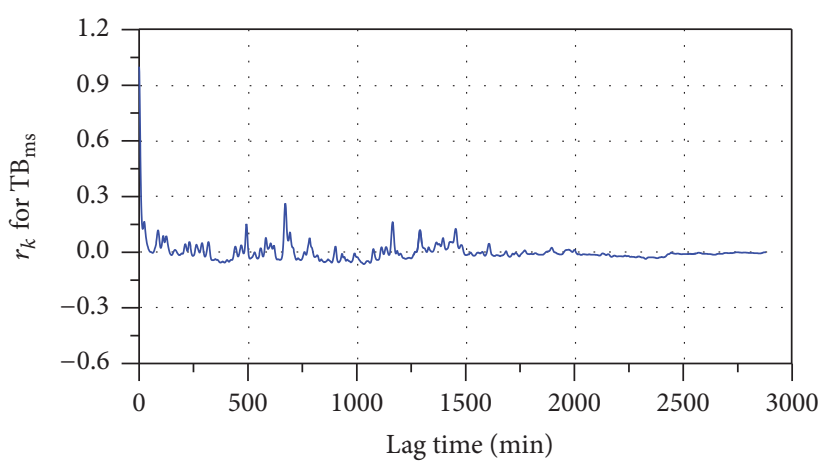

(e)

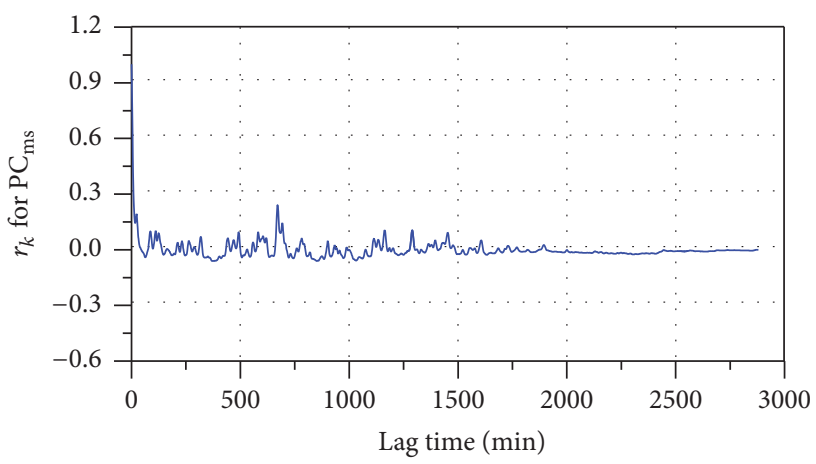

(g)

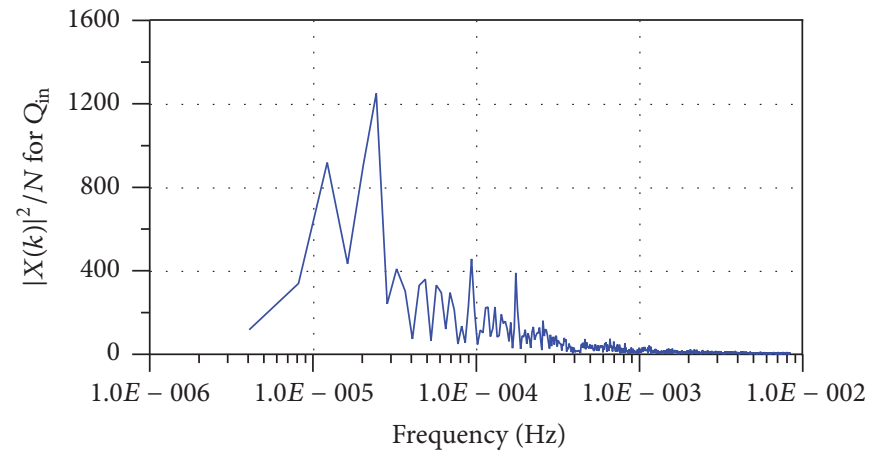

(b)

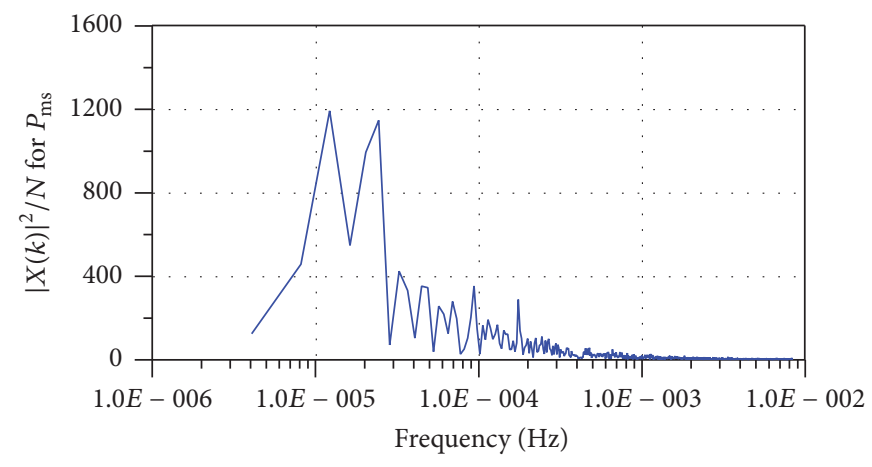

(d)

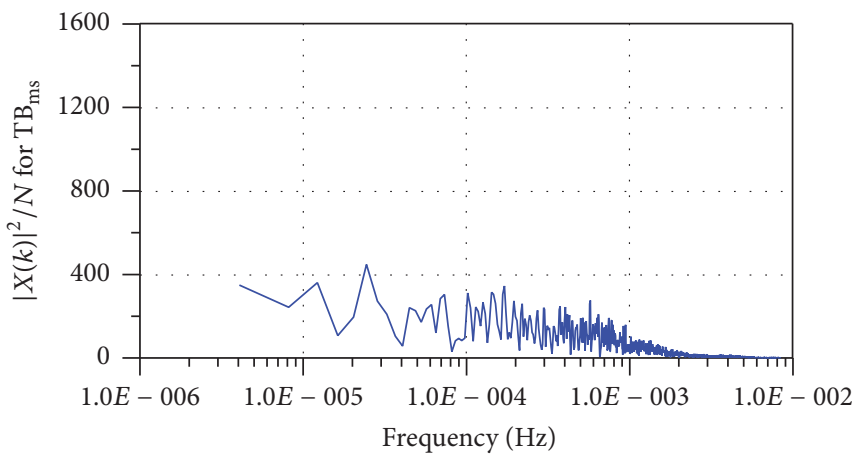

(f)

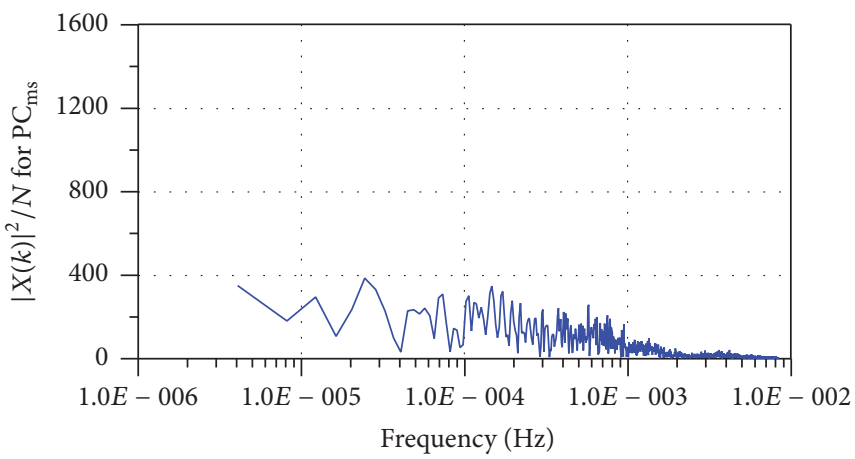

(h)

Figure 4: Autocorrelations and power spectral densities for (a)-(b) flow at the inlet, (c)-(d) pressure at monitoring station, (e)-(f) turbidity at monitoring station, and $(\mathrm{g})-(\mathrm{h})$ particle count of $2-4 \mu \mathrm{m}$ size regime at monitoring station. 


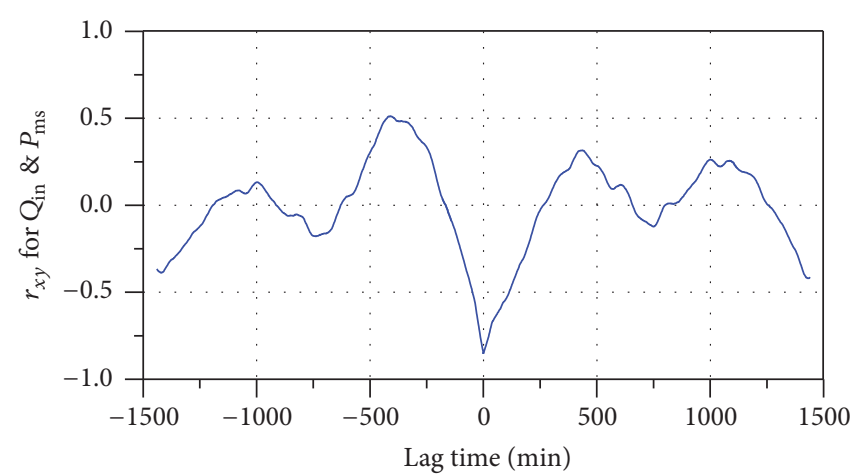

(a)

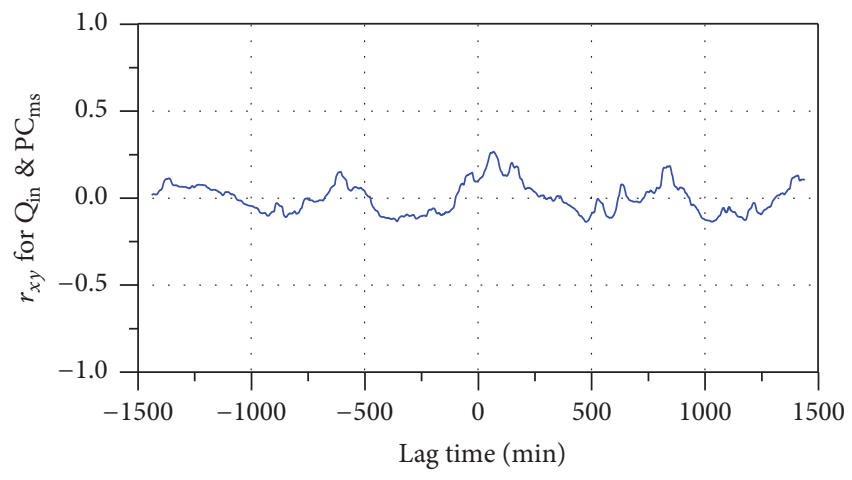

(c)

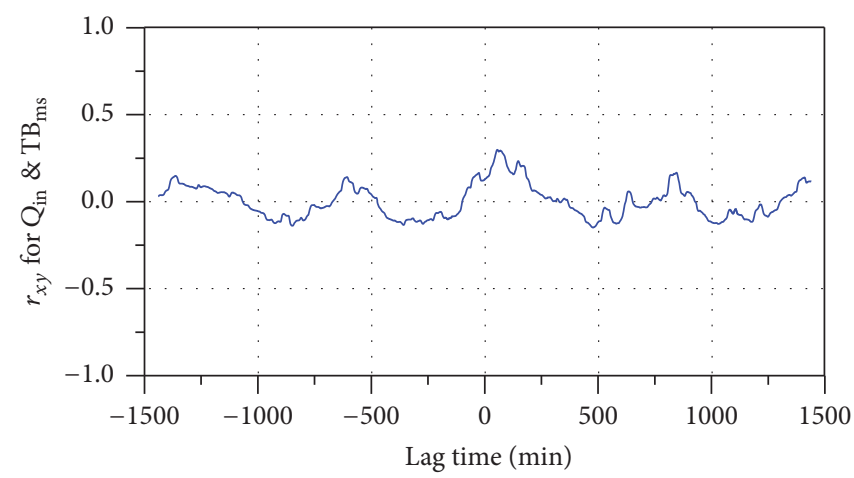

(b)

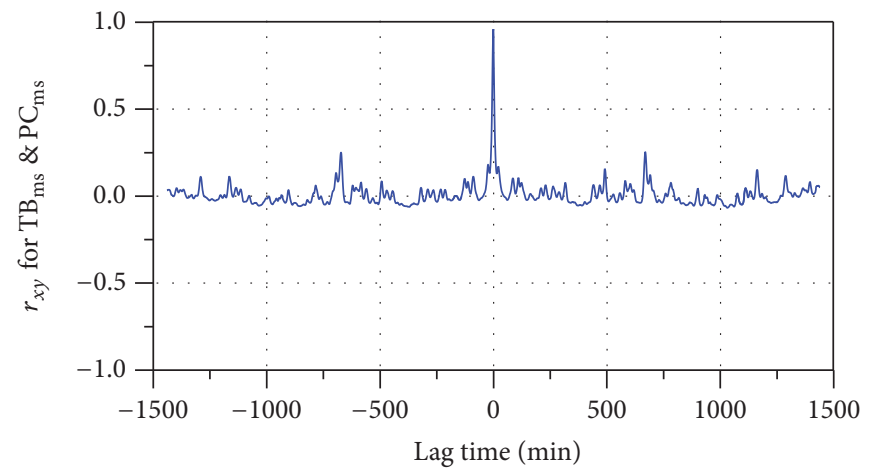

(d)

FIGURE 5: Cross-correlations for (a) pressure at monitoring station with respect to flow, (b) turbidity with respect to flow, (c) particle count $(2-4 \mu \mathrm{m})$ with respect to flow, and (d) particle count $(2-4 \mu \mathrm{m})$ with respect to turbidity.

TABLE 2: Elemental concentration of samples through ICP-AES.

\begin{tabular}{|c|c|c|c|c|c|}
\hline \multirow{2}{*}{ Element } & \multicolumn{5}{|c|}{ Concentration $(\mathrm{mg} / \mathrm{L})$} \\
\hline & 1st sample & 2nd sample & 3rd sample & 4th sample & 5th sample \\
\hline $\mathrm{Fe}$ & 334,401 & 116,862 & 234,617 & 42,633 & 137,249 \\
\hline $\mathrm{Cu}$ & 1,115 & 314 & 531 & 102 & 319 \\
\hline $\mathrm{Mn}$ & 2,938 & 1,006 & 2,008 & 332 & 867 \\
\hline $\mathrm{Zn}$ & 4,709 & 583 & 1,262 & 131 & 377 \\
\hline $\mathrm{Ca}$ & 9,752 & 2,667 & 6,083 & 983 & 2,831 \\
\hline $\mathrm{Al}$ & 37,554 & 6,793 & 13,275 & 2,286 & 6,258 \\
\hline $\mathrm{Mg}$ & 1,484 & 364 & 767 & 138 & 428 \\
\hline $\mathrm{Si}$ & 38,312 & 9,179 & 29,932 & 4,262 & 5,276 \\
\hline
\end{tabular}

power spectrum, and cross-correlation. Furthermore, the chemical composition of particles suspended in the water, which can cause high turbidity by incorporation into the water supply from the inner wall of pipelines, was analysed with ICP-AES for sampled particulates collected from an installed particulate filtration system. Based on the results of this investigation, the following conclusions were drawn:

(1) The intermittent refill of drinking water by largedemand customers disturbed the standard diurnal demand pattern significantly, with a peak flow between 100 and $250 \%$ of the mean flow rate in the field study of the NS-2 DMA. This unwanted peak flow magnitude can decrease the operating pressure from 0.5 to $1.0 \mathrm{kgf} / \mathrm{cm}^{2}$ and may eventually induce service interruptions if the collection inlet is located near a low-pressure DMA.

(2) The time series data explained that hydraulic transient events, induced by abrupt flow transmission, caused sudden increases in both particle count and turbidity by relating low turbidity to periods of stable flow. The resulting turbidity peaks can exceed the MCL values of 0.5 to $1.0 \mathrm{NTU}$. A maximum turbidity of 2.27 NTU was recorded, which is 17 times the average turbidity; this risks the discharge of particulates at customer taps. In addition, fine particles of $2-4 \mu \mathrm{m}$ in diameter were vulnerable to the disturbances of 
hydraulic transient events, based on the analysis of online particle count results.

(3) The statistical results of autocorrelation, spectral power spectrum, and cross-correlation showed some degree of similarity between the hydraulic parameters (flow and pressure) and the water quality parameters (turbidity and particle count), which was proven by the presence of nine extreme values in the crosscorrelations of flow-pressure, flow-turbidity, and flow-particle count. The intermittent filling interval of $6.7 \mathrm{~h}$ was detected through autocorrelation analysis; furthermore the similarities of the flow-pressure and the turbidity-particle count were reexamined through power spectral density analyses. A strong crosscorrelation coefficient approaching 1 is observed in the flow-pressure and turbidity-particle count analyses. However, further analysing algorithms such as dynamic time warping are necessary to measure such similarities.

(4) Chemical element analysis using ICP-AES showed that Fe was the major constituent of the particulates, originating from metallic oxide induced by corroded pipes, and that $\mathrm{Si}$ and $\mathrm{Al}$ are other major ingredients from soil and Al-containing coagulants, respectively.

\section{Competing Interests}

The authors declare no conflict of interests.

\section{Acknowledgments}

This work is financially supported by the Korea Water Resources Corporation (K-water).

\section{References}

[1] A. K. Deb, Y. J. Hasit, and F. M. Grablutz, Distribution System Performance Evaluation, American Water Works Association, Denver, Colo, USA, 1995.

[2] T. M. Walski, D. V. Chase, D. A. Savic, W. Grayman, S. Beckwith, and E. Koelle, Advanced Water Distribution Modeling and Management, Haestad Methods, Haestad press, Waterbury, Conn, USA, 1st edition, 2003.

[3] C. N. Joo, J. Y. Koo, and M. J. Yu, "Application of short-term water demand prediction model to Seoul," Water Science \& Technology, vol. 46, no. 6-7, pp. 255-261, 2002.

[4] S. Alvisi, M. Franchini, and A. Marinelli, "A short-term, patternbased model for water-demand forecasting," Journal of Hydroinformatics, vol. 9, no. 1, pp. 39-50, 2007.

[5] D. Y. Choi, C.-H. Bae, D. Kim, and J. Kim, "Impacts of largedemand customer on water distribution system," in Proceedings of the 16th International Conference on Water Distribution System Analysis (WDSA '14), pp. 220-224, Bari, Italy, July 2014.

[6] C. Evins, J. Liebeschuetz, and S. M. Wilkiams, Aesthetic Water Quality Problems in Distribution Systems: A Source Document for the Water Mains Rehabilitation Manual, Water Research Centre, Swindon, UK, 1990.
[7] V. Gauthier, B. Gérard, J.-M. Portal, J.-C. Block, and D. Gatel, "Organic matter as loose deposits in a drinking water distribution system," Water Research, vol. 33, no. 4, pp. 1014-1026, 1999.

[8] G. J. Kirmeyer, M. Friedman, J. Clement et al., Guideline Manual for Maintaining Distribution System Water Quality, American Water Works Association, Denver, Colo, USA, 2000.

[9] J. B. Boxall, P. J. Skipworth, and A. J. Saul, "Aggressive flushing for discolouration event mitigation in water distribution networks," Water Science \& Technology: Water Supply, vol. 3, no. 1-2, pp. 179-186, 2003.

[10] S.-H. Chae, D.-H. Kim, D. Y. Choi, and C.-H. Bae, "Establishment of a practical approach for characterizing the source of particulates in water distribution systems," Water (Switzerland), vol. 8, no. 2, article 49, 2016.

[11] J. H. G. Vreeburg, P. G. Schaap, and J. C. Van Dijk, "Particles in the drinking water system: from source to discolouration," Water Science \& Technology: Water Supply, vol. 4, no. 5-6, pp. 431-438, 2004.

[12] H. Shamsaei, I. Othman Jaafar, and N. E. A. Basri, "Effects velocity changes on the water quality in water distribution systems," Research Journal of Applied Sciences, Engineering and Technology, vol. 5, no. 14, pp. 3783-3790, 2013.

[13] X. C. Carrera, A new tool for characterisation of particulate material in water distribution systems [Ph.D. thesis], Universitat Politècnica de Catalunya, Barcelona, Spain, 2008.

[14] G. Liu, F. Q. Ling, A. Magic-Knezev, W. T. Liu, J. Q. J. C. Verberk, and J. C. Van Dijk, "Quantification and identification of particle-associated bacteria in unchlorinated drinking water from three treatment plants by cultivation-independent methods," Water Research, vol. 47, no. 10, pp. 3523-3533, 2013.

[15] J. D. Salas, J. W. Delleur, V. Yevjevich, and W. L. Lane, Applied Modeling of Hydrologic Time Series, Water Resources, Littleton, Colo, USA, 1st edition, 1980.

[16] P. M. Berthouex and L. C. Brown, Statistics for Environmental Engineers, Lewis Publishers, Boca Raton, Fla, USA, 1st edition, 1994.

[17] Y. Filion, B. Adams, and B. Karney, "Cross correlation of demands in water distribution network design," Journal of Water Resources Planning and Management, vol. 133, no. 2, pp. 137-144, 2007.

[18] S. B. M. Beck, M. D. Curren, N. D. Sims, and R. Stanway, "Pipeline network features and leak detection by crosscorrelation analysis of reflected waves," Journal of Hydraulic Engineering, vol. 131, no. 8, pp. 715-723, 2005.

[19] J. Q. J. C. Verberk, L. A. Hamilton, K. J. O’Halloran, W. van der Horst, and J. Vreeburg, "Analysis of particle numbers, size and composition in drinking water transportation pipelines: results of online measurements," Water Science \& Technology: Water Supply, vol. 6, no. 4, pp. 35-43, 2006.

[20] T. L. Gerke, J. B. Maynard, M. R. Schock, and D. L. Lytle, "Physiochemical characterization of five iron tubercles from a single drinking water distribution system: possible new insights on their formation and growth," Corrosion Science, vol. 50, no. 7, pp. 2030-2039, 2008. 


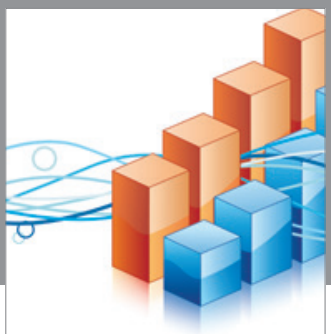

Advances in

Operations Research

vatem alat4

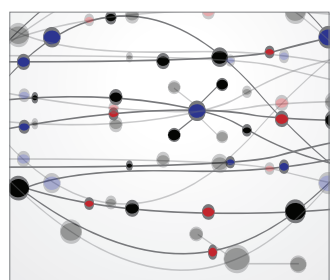

\section{The Scientific} World Journal
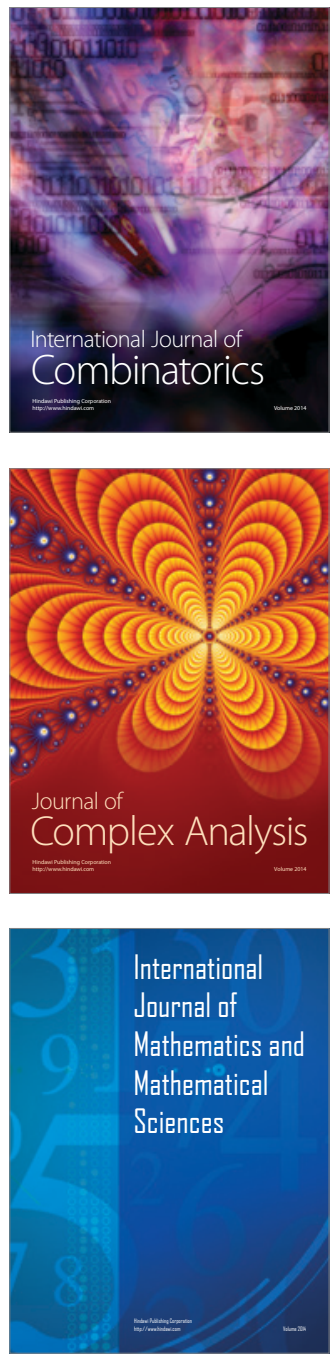
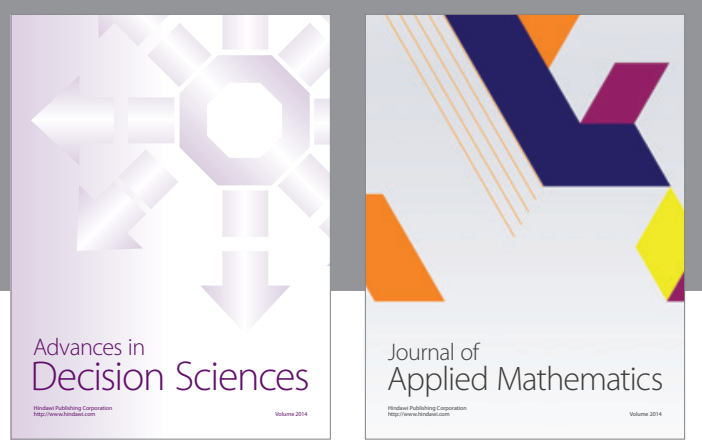

Algebra

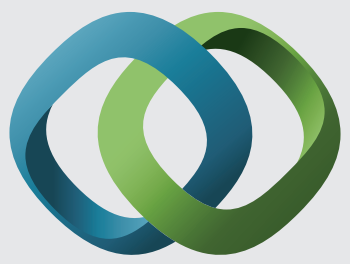

\section{Hindawi}

Submit your manuscripts at

https://www.hindawi.com
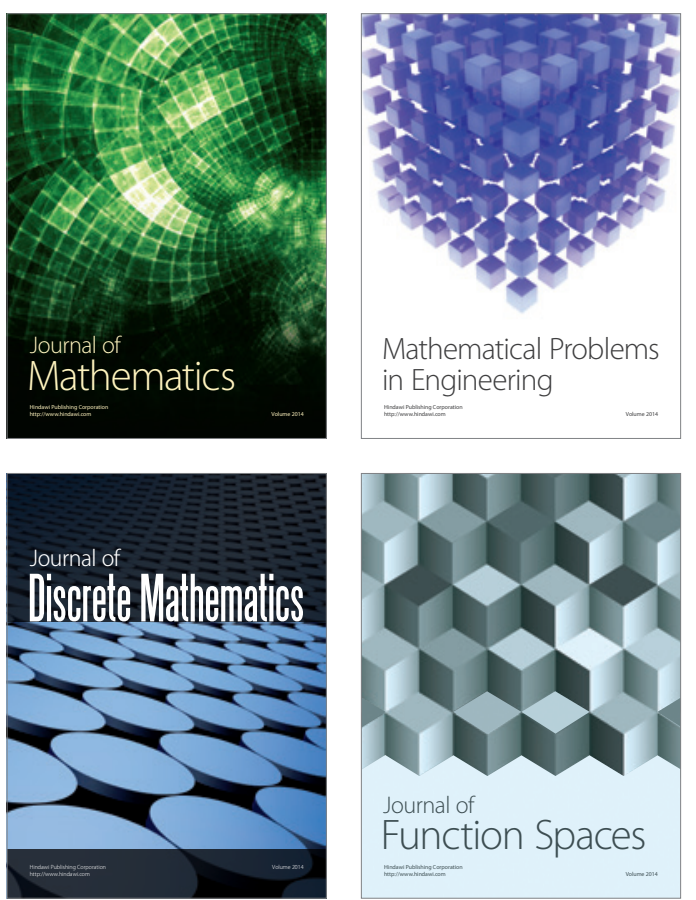

Mathematical Problems in Engineering
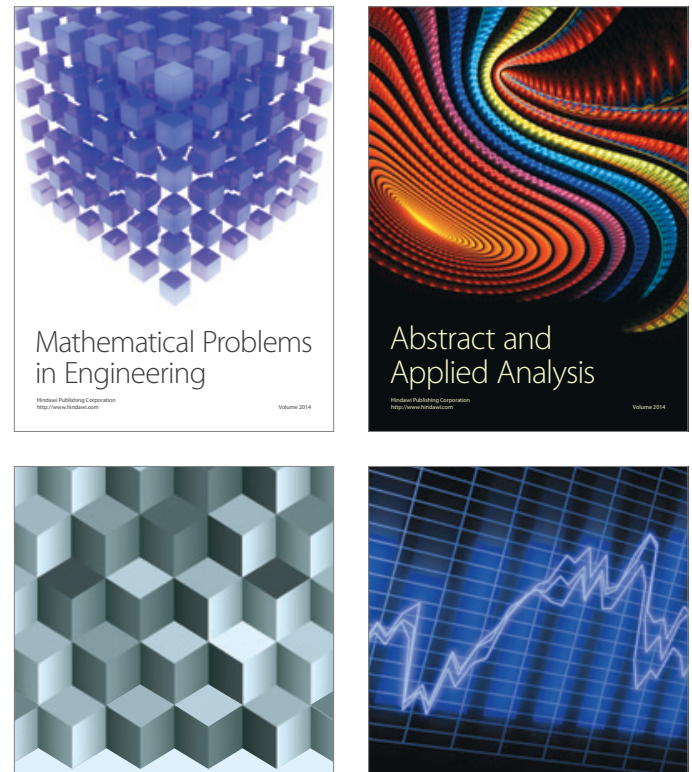

Journal of

Function Spaces

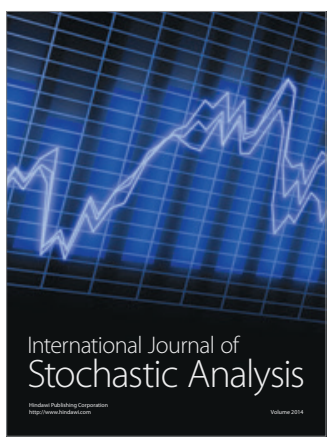

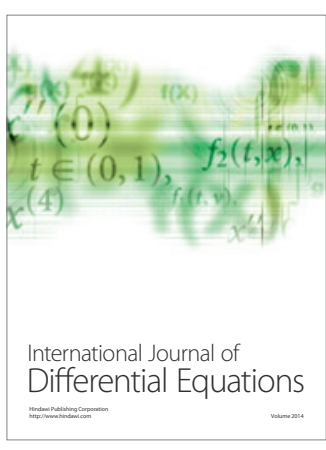
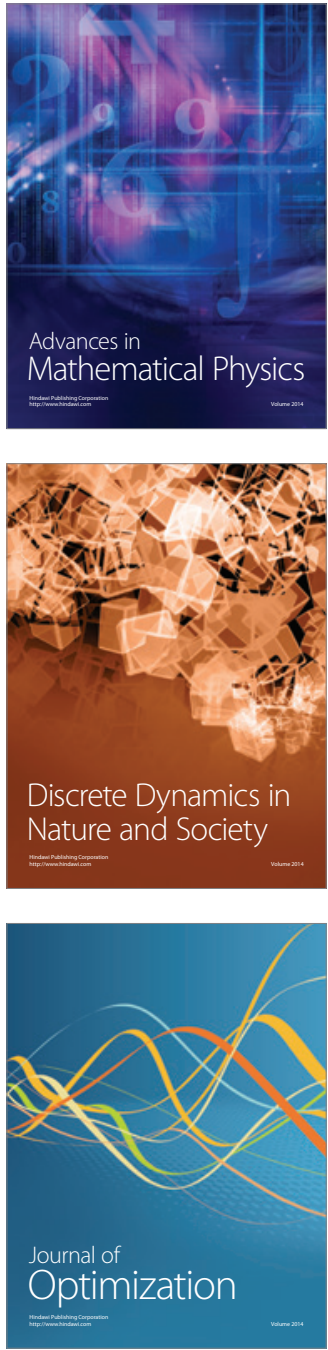